\title{
Impact of Business Processes Reengineering on Employees Performance in Jordanian Electricity Distribution Company
}

\author{
Dr. Mohammad Izzat Al-Halalmeh \\ Associated Professor \\ Business Administration \\ Al-Balqa Applied University \\ Princess Alia University College \\ Management and Finance Department
}

\begin{abstract}
World witnessed basic and rapid changes that affect human life different aspects particularly in managerial work, since such changes affect managerial organizations future, and impose new challenges represented by organizations efforts to absorb and integrated these changes in their business and to cope with new thoughts and attitudes Reengineering has gained an interesting attention during the last decade The majority of companies in all parts of the world set certain strategies in order to satisfy customers by Re-engineering process adoption. The study focused on investigating re-engineering process and its effects on employees' performance. The study population comprised of employees at Electricity Distribution Company. The study used a descriptive analytical methodology... A questionnaire was designed and distributed to collect the data. The study used comprehensive sampling technique in selecting sample's subjects. Regression analysis was used to find out the impact of reengineering process on employees performance. The study population consisted of all employees in Jordanian Electricity Distribution Company, The study concluded that there is a statistically significant impact at 0.05 $\geq \alpha)$ ) level for reengineering with its dimensions collectively on Jordanian Electricity distribution company employees, Furthermore the study concluded that there is an impact of reengineering dimensions separately (procedures simplification, improving services quality, process implementation, and information technology) on Jordanian Electricity distribution company. The study recommended that there is a need for reengineering all departments and units that suffer from performance problems according to reengineering approach roles for the purpose of making core changes that increase the process efficiency in raising performance level and increasing its efficiency. The research also recommended that there is a need to take into account the factors that contribute to the success of reengineering process and which is appropriate to the nature of Electricity distribution Company.
\end{abstract}

Keywords: Reengineering, Procedures simplification, Services Quality, Processes implementation, Information Technology, Employees Performance

\section{Introduction}

The use of reengineering process approach is a step towards finding more effective ways and means to address the problems experienced by organizations. Experiences from reengineering process approaches provide those interested in improving organizational performance with new perspectives to address the organizational deterioration situation. Optionally, organizations development is no longer a matter of survival that can essentially be renounced by selection, but it has become a regulated condition and not failure. Using reengineering approach is an approach to broad change, focuses on changing the core processes of the organization, and seeks to make all processes more efficient by typically combining their design, regardless of tasks, Re-engineering needs a new look of management, perhaps a new philosophy. In order to succeed in re-thinking, Modern and leading institutions seek to make fundamental changes and modernize their operations and information structure to support decision-making, to cope with changes in their surrounding environment and to increase their competitiveness and survival. The change is essentially aimed at giving organizations the flexibility and capacity to achieve their objectives and enhance their culture In order to serve its future vision and strategic plan, enhance its competitive advantage, and there are many modern management methods aimed at achieving such objectives as total quality management, reengineering of administrative processes, 
For the recent technological development and the emergence of the Internet, the process engineering method has been use process reengineering has started as a private sector technique to help organizations fundamentally to rethink how they do their work to improve customer service dramatically, reduce operating costs, and become competitive. Process reengineering is the analysis and redesign of workflow within and between companies. After the global recession in the early 1980s, many organizations and companies around the world tried to revitalize their performance.

Amer and Qendeel (2010) indicated that reengineering process is a modern management approach that aims to make a basic and quick change in the organizations through redesigning strategic operations, policies, organizational structures, values and supporting hypothesis in nontraditional form

According to Hailekiros \& Ajit (2012), business reengineering is a dramatic change that generally represents organizational structures, management system, employee responsibilities, empowerment, performance measures, incentive system, skills development and the use of information technology. The successful process reengineering model can lead to significant cost reductions, improvements in quality and customer services. On the other hand, process reengineering projects may fail to meet the high expectations inherent in restructuring in some organizations, destroying morale and the momentum of lifelong staff due to poor implementation of process reengineering.

\section{Background}

Global business nowadays is facing intensive competition. Therefore most companies restore to reengineering process for the purpose of being efficient and competitive in their business. Based on Business Process Reengineering is considered as competitive tool that business organizations use in order to help organizations in building themselves by using new technologies business solutions. Therefore any firm wishes to increase its efficiency, enhance productivity should adopt dramatic change regarding its design (Graham, 2010).

Business process reengineering began as a private sector technique to help organizations fundamentally rethink how they do their work in order to dramatically improve customer service, cut operational costs, improve productivity, optimize costs and become world-class competitors. A key stimulus for reengineering has been the continuing development and deployment of sophisticated information systems and networks. Leading organizations are becoming bolder in using this technology to support innovative business processes, rather than refining current ways of doing work (Hope, et al, 2015).

\section{Study statement}

This study is an attempt to investigate the impact of processes re-engineering on Jordanian Electricity Distribution Company employees performance because the services provided by the company affect all citizens to whom the company provides its services. This requires improving employee's performance in order to give a good picture of the company. Therefore following main question can be formulated: What is the effect of processes reengineering in Jordanian Electricity Distribution Company employees performance?

\section{Study Purpose}

The study aimed to investigate the impact of processes re-engineering on Jordan Electricity Distribution Company employees performance in addition to the following sub-goals

1- To understand the concept of processes re-engineering in Jordanian Electricity Distribution Company

2- To specify the impact of process reengineering dimensions represented by (simplifying procedures, improving service quality, applying new processes and applying IT) on employees performance.

\section{The importance of the study}

The importance of the study is generated from the following:

1. The importance of the selected of this company for the study, Electricity Distributed Company, which is considered as one of the most important and efficient company in Jordan.

2. It provides a theoretical model that can improve the understanding of the nature of the relationship business process reengineering and employees performance.

3. There is a lack of studies that measure the extent of understanding of business process reengineering as an enabler of employees performance in Jordan. 
4. The practical significance of the study is that the results of the surveyed company can benefit from the business process reengineering in the employees performance and the formulation of strategies to take advantage of the process to achieve the company aims in the market.

\section{The main objectives of this research are:}

A. To propose a model of how the business process reengineering may cause the employees performance.

B. To determine the impact of the business process reengineering on employees performance in Electricity Distributed Company.

C. To write a theoretical framework for the study variables in this research.

D. To provide some recommendations.

\section{Research methodology}

There are two approaches that can be applied in a research, quantitive and qualitative. In qualitative approach researcher can get greater understanding of the concept instead of providing specific measurement the qualitative approach mainly is concerned with words, observations, namely interpretations. The researcher has adopted the quantitative approach in this research for the purpose of assessment of the different opinions on Facebook advertisement

An analytical, descriptive methodology approach was followed in this research as it is suitable to the objectives of the research. A systematic method for data analysis is implemented to investigate and explain the relationships and connections between the study variables. The research methodology field has been used to cover the practical side of this research, by answering questions, examining the validity of hypotheses of the study, and getting their results out of a questionnaire that was created for the purposes of the study based on the steps of scientific norms.

\section{Research Design}

Research used descriptive survey method to collect related to research variables (reengineering and employee performance). The method describes the research statement through self-administrated questionnaires, because the aim of the research is find out the impact of reengineering process on employee performance .The questionnaire was designed in Arabic language for those who don't master English Language and then translated to English

\section{Data Collection Methods}

Two types of data collection are used. Secondary data and primary data, Collection of secondary data collection methods include every data resource that is available to researcher to facilitate obtaining the information needed for purposes of the research. Primary data can be collected by questionnaire

\section{Secondary Data}

Secondary data will be collected for the purpose of solving the problem which the research is handling. It will be collected from various resources such as: books, journals, newspapers, periodicals, and the web net to collect the required secondary data,

\section{Primary Data Collection}

The primary data will be collected through a questionnaire which will be designed by the researcher according to research objective

\section{Research Instrument}

The survey instrument which will be a self-administrated questionnaire will be used to collect the required data, because it is quick and cost effectiveness, high responses rate and law bias The questionnaire will be designed in three parts with five-points liker scale that ranged from strongly agree $=5$ scores, agree $=4$ scores, neutral $=3$ scores, disagree $=2$ scores and strongly disagree $=1$ score. The questionnaire statements were derived from the previous studies that match with the research topic. All statement was formed for the purpose of meeting research objectives.

\section{Study Hypotheses}

Based on study problem and previous studies results, the following main hypothesis can be formulated:

\section{The main hypothesis:}


Ho: There is no statistically significant impact at $(\alpha \leq 0.05)$ level of business processes re-engineering application with its dimensions (procedures simplification, improving service quality, applying new processes and applying IT) on Jordan Electricity Distribution Company employee's performance.

\section{The following sub-hypotheses were derived:}

Ho-1 There is no statistically significant impact at $(\alpha \leq 0.05)$ level of procedures simplification on Jordanian Electricity Distribution Company employee's performance.

Ho-2 There is no statistically significant impact at $(\alpha \leq 0.05)$ level of improving service quality on Jordanian Electricity Distribution Company employee's performance.

Ho-3 There is no statistically significant impact at $(\alpha \leq 0.05)$ level of applying new process on Jordanian Electricity Distribution Company employee's performance.

Ho-4 There is no statistically significant impact at $(\alpha \leq 0.05)$ level of applying information technology on Jordanian Electricity Distribution Company employee's performance

\section{Study Model:}

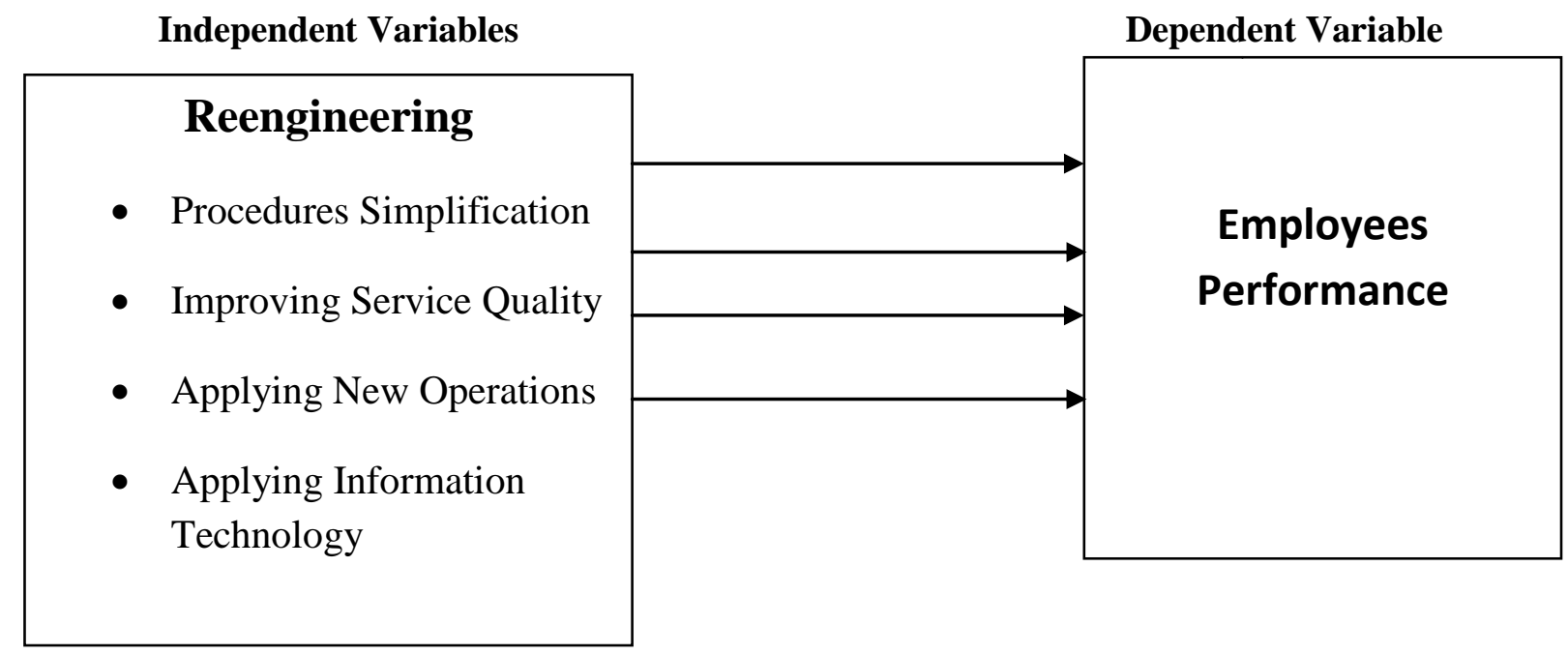

Source: Dodakh 2017, Khodhari and Kasasbeh 2015 and Abu Mash 2011.

\section{Population and Sampling}

The research population consisted of (207) employees of the Electricity Distribution Company. A random sample of (60) employees was selected. 57 questionnaires were recollected, three of which were disregarded due to incompleteness, therefore the sample was (54) employees only.

\section{Concept of process reengineering}

Concept of re-engineering process emerged in early 1990s when two American authors Michael Hammer and James Champie launched reengineering as a title for their famous book "Organization reengineering." Since then, reengineering has revolutionized modern management science with its unconventional ideas and an explicit call for radical revision of all activities, procedures and strategies that have been established by many organizations and companies operating in our world today. Perhaps the most important call for this concept is to invite employees to creativity in their work and get rid of repetition and monotony constraints and view surrounding issues incomprehensive view that helps in revoking hiding creativity energies in every individual (Al-Otaibi and Al-Hamali, 2004: 6).

The concept of Business Process Reengineering is one of development approaches. It focuses on rapid redesign and radical change of strategic business processes with added value, as well as systems, policies and organizational structures for the purpose of performance improving and increasing productivity in the organization, and increasing customer satisfaction (Qarouti, 2000: 343).

Process reengineering is defined as "the radical and rapid redesign of strategic and value-added management processes, systems, policies and structures that assist these processes, with the goal of achieving high organizational objectives" (Al-Sakarna, 2009: 150). ) 
While Jad Al-Rab(2009, p166) defined processes reengineering as "the organization's leadership and its top management innovative thinking, as well as their firm desire to make radical changes or at least those who are impacting processes activities that affect the organization, for the purpose of continuous quality improvement and performance, reducing costs and achieving high levels of customer satisfaction.". It is also defined as the redesign of business practices to achieve strong development in performance standards such as cost, quality, and rapid service. "(Sudhakar, 2010, p29). Process reengineering is" the work overall shift, unrestricted restructuring of all Business processes, techniques used, management systems, organizational structure and organizational values, for the purpose of achieving qualitative leapfrogging across the organization "(Jalali, et al., 2013).

Business organizations use re-engineering from three main forces represented by: customers focus by identifying their needs, fulfilling their desires, and work design according to their needs and competition, which is represented by work method and tools and results by enabling employees to carry out their tasks according to the needs of customers and finally the change which is considered as a rule that should be adopted by all organizations to re-engineer their process (Al-Sakarna 2009)

\section{Objectives of reengineering}

Ahmad (2003) indicated that reengineering process aimed to achieve the following objectives Achieving a radical change in performance:

1. Reengineering aims to radically change performance and change System and tools for the work

2. Speed: Reengineering aims to achieve the required speed that enables any an organization to carry out its work according to the schedule and by providing a modern information and communication network that facilitates access to information necessary and rapid decision-making.

3. Quality Reengineering aims to improve the quality of products and services provided by the institution or the organization to meet the requirements and needs

4. Cost reduction: Reengineering aims at concealing the financial cost of any production or service process by focusing mainly on eliminating unnecessary processes

5. Focus on actual demands: Reengineering aims to guide the institution or the entity to identify actual demands from them and to provide the necessary means to enable them to

\section{Reengineering Process Principals}

Reengineering process is based on the following principles

1. Reengineering is based on redesign the individual proceeds with its full stages and steps from the start poet up to the end

2. Reengineering is based on new information technology (information system), using decentralized in its use

3. Reengineering seeks to integrate sub-tasks into a single task

4. Authorizing staff to perform their functions efficiently after reengineering

5. Providing sufficient flexibility in implementing operation stages and steps

6. Designing the operation in a form that enables it to do more than work

7. Reduce number of audits and reviews to provide speed in performance

8. Reengineering seeks to increase competitiveness ability of large organizations using advanced technologies. (Kurdi, 2010, 3).

Many researchers handled the reengineering topic, for example Kahlut (2017) investigates the concept and reality of processes re-engineering, tasks and related activities, and to investigate the relationship between re-engineering in Palestinian universities in Gaza and achieve their competitive advantage... The study concluded that Palestinian universities applied processes re-engineering. And there is at a positive relationship between re-engineering and competitive advantage and there is a statistically significant impact on the following variables (organizational culture, commitment and support of university leadership) on competitive advantage... Dodakh (2017) indicated that there is an impact of business processes re-engineering in improving cost and time and improving the efficiency of electrical service. In this context Hope, et al, (2015) found a significant relationship between business process reengineering (change management, process redesign, management commitment, and IT infrastructure) and overall organizational performance of the selected Courier Service Organizations. They also concluded that reengineering process is a vital model for improvement in operational performance to achieve long-term growth and competitive advantage. 
Moreover Al Khudhari and Al- Kasasbeh (2015) found that there are effects of independent variables (Processes reengineering, orders flow, and human resources operations on performance scales of pharmaceutical sector). Amirta and Sheriff (2015) indicated that the majority of organizations applied reengineering was medium sized enterprises in the Indian market while small and large did not try this approach. Sharma and Kant (2015) argued that most of the re-engineering initiatives were at the beginning of the new technology application initiatives, which enhance the idea that technology plays a major role in re-engineering approach and that the role of technology is limited to suitability and allocation to fit the new processes

\section{Data analysis}

\section{Instrument Reliability}

Cranach Alpha Approach is used in order to ensure that the questionnaire measures the factors to be measured; the researcher tested the extent of the paragraphs internal consistency, where the cohesion of the scale was rated by calculating the coefficient Cranach's alpha. Table (1) indicates the achieved results

\section{Table (1)}

$\begin{array}{lll}\text { Cranach Alpha Coefficient Variable } & \text { Items } & \text { Cronbach Alpha } \\ \text { The whole instrument } & 27 & .932 \\ \text { Procedures Simplification } & 5 & .938 \\ \text { Improving Service quality } & 5 & .862 \\ \text { Applying New operations } & 5 & .924 \\ \text { Information Technology } & 5 & .733 \\ \text { Employees Performance } & 7 & .844\end{array}$

\section{Normality Distribution test}

Normal data distribution test was carried out to investigate if data are within normal distribution or not. Kolmogorov-Smirnov Test was made. Such test is used for the purpose of testing test the normality distribution of data when number of cases is greater than (50), and normality distribution conditions that the value of K-S is less than (5), and the values of Skewness coefficient is less than (1)

Table (2) Normality distribution

\begin{tabular}{|l|l|l|l|l|}
\hline \multicolumn{1}{|c|}{ Variables } & \multicolumn{1}{c|}{ Mean } & \multicolumn{1}{c|}{ S. Deviation } & K-S & \multicolumn{1}{c|}{ Skewness } \\
\hline Procedures Simplification & 4.4444 & .54898 & -.901 & -.372 \\
\hline Improving Service quality & 4.3926 & .51537 & -.254 & -.349 \\
\hline Applying new operations & 4.4370 & .59568 & -.456 & -.569 \\
\hline Applying Information Technology & 4.1815 & .67098 & -.192 & -.465 \\
\hline Employees Performance & 3.9259 & .96202 & .527 & -.995 \\
\hline
\end{tabular}

Table (2) indicates that the values of Kolmogorov-Smirnov (K-S) test for all dimensions are less than (5). Table also indicates that all values Skewness coefficient (Skewness) is less than (1). This means that data is normally distributed.

Table (3) Description of the Characteristics of the Sample Study

\begin{tabular}{|l|l|l|l|}
\hline Variable & Options & Frequency & Percent \\
\hline \multirow{3}{*}{ Gender } & Male & 40 & 74.1 \\
\cline { 2 - 4 } & Female & 14 & 25.9 \\
\hline \multirow{5}{*}{ Age } & Less than 25 & 5 & 9.3 \\
\cline { 2 - 4 } & 25 to less than35 & 21 & 38.9 \\
\cline { 2 - 4 } & 35 to less than45 & 18 & 33.3 \\
\cline { 2 - 4 } & $45+$ & 10 & 18.5 \\
\hline \multirow{5}{*}{ Education Level } & Diploma & 12 & 22.2 \\
\cline { 2 - 4 } & Bsc & 36 & 66.7 \\
\cline { 2 - 4 } & Msc & 6 & 11.1 \\
\cline { 2 - 4 } & Department Manager & 4 & 7.4 \\
\cline { 2 - 4 } & Deputy department Manager & 6 & 11.1 \\
\cline { 2 - 4 } & Section Head & 10 & 18.5 \\
\cline { 2 - 4 } & Employee & 34 & 63.0 \\
\hline \multirow{3}{*}{ Expears } & Less than 5 years & 8 & 14.8 \\
\cline { 2 - 4 } & 5 to less than 10 years & 18 & 33.3 \\
\cline { 2 - 4 } & 10 to less than 15 years & 20 & 37.0 \\
\cline { 2 - 4 } & $15+$ & 8 & 14.8 \\
\hline
\end{tabular}


Table (3) indicates that $(74.1 \%)$ of the sample were males while females were $(25.9 \%)$.

Such results can be attributed due to the fact that the nature of the company business needs males more than females

As for age, $9.3 \%$ are (less than 25 years), $38.9 \%$ are between (25 to 35), 33.3 are between (35-45). Finally, the age group (45 and over) was $18.5 \%$ individuals. Results indicate that the majority of the sample is less than 45 years. Table (3) indicates that $66.7 \%$ of the sample had bachelor's degree while $(11.1 \%$ had master's degree Therefore the majority of the sample are university graduate, this due that the company works needs qualified staff With respect to job, Table (1) indicated that $7.4 \%$ Of the sample were managers $(11 . .1 \%)$ were departments heads $18.5 \%$ were deputy managers and $63 \%$ were employees. . As for the experience, table (3) showed that (14.8\%) had an experience (less than 5 years). While 33.3\% has an experience (5 to less than 10 years) and (37\%) with experience (10 to less than 15), and (14.8\%) with an experience (15 years and more).

Table (4) Means and standard deviations of sample's responses regarding Procedures Simplification

\begin{tabular}{|l|l|l|l|l|l|}
\hline No. & Question & Mean & S.D. & Rank & Level \\
\hline $\mathbf{1}$ & Reducing papers for service obtaining & 4.48 & .574 & $\mathbf{3}$ & High \\
\hline $\mathbf{2}$ & Provide the service as soon as possible & 4.50 & .575 & $\mathbf{1}$ & High \\
\hline $\mathbf{3}$ & The company deals with all subscribers with the same standards & 4.50 & .575 & $\mathbf{1}$ & High \\
\hline $\mathbf{4}$ & Easiness of communication with the company & 4.37 & .653 & $\mathbf{4}$ & High \\
\hline $\mathbf{5}$ & Transactions termination of in time & 4.37 & .681 & $\mathbf{4}$ & High \\
\hline & Grand Mean & 4.44 & .54898 & & High \\
\hline
\end{tabular}

Table (4) indicates that the means of subjects' responses to the statements that measure procedures simplification ranged between (4.37-4.50)). This means that subjects responses regarding the procedures simplifications attitudes is high .Table also indicates that respondents' level of agreement to all statements are of high level The two statements 2 and 3 "providing service with less time, and the company deals with all subscribers with the same standards "ranked the first. This indicate that reengineering affect the procedural simplification which reflected positively on organization performance, while the two statements 4 and 5 " Easiness of communication with the company and Transactions termination of in time .It is important to mention that the grand mean of all statements was (4.44), which corresponds to high level of agreement among respondents.

Table (5) Means and standard deviations of sample's responses regarding improving service quality

\begin{tabular}{|l|l|l|l|l|l|}
\hline No. & Question & Mean & S.D. & Rank & Level \\
\hline $\mathbf{6}$ & The speed in determining the necessary papers to participate & 4.52 & .540 & $\mathbf{1}$ & High \\
\hline $\mathbf{7}$ & Provide solutions to the problems facing subscribers & 4.20 & .711 & $\mathbf{5}$ & High \\
\hline $\mathbf{8}$ & Knowing the time required to complete transactions & 4.43 & .602 & $\mathbf{3}$ & High \\
\hline $\mathbf{9}$ & Knowing the follow-up mechanisms for subscription transactions & 4.46 & .573 & $\mathbf{2}$ & High \\
\hline $\mathbf{1 0}$ & Providing high quality service to achieve subscribers satisfaction & 4.35 & .756 & $\mathbf{4}$ & High \\
\hline & The Grand means & 4.39 & .515 & & High \\
\hline
\end{tabular}

Table (5) indicates that the means of subjects' responses to the statements that measure procedures simplification ranged between (4.37-4.50)). Table also indicates that respondents' level of agreement to all statements are of high level The two statements 2 and 3 " providing service with less time, and the company deals with all subscribers with the same standards "ranked the first, while the two statements 4 and 5 mention that the grand mean of all statements was (4.44), which corresponds to high level of agreement among respondents.

The results indicated that company's customers are more interested in simplification of company's procedures related to the service they received from the company and how the company handles their problems.

Table (6) Means and standard deviations of sample's responses regarding implementing new operations

\begin{tabular}{|l|l|l|l|l|l|}
\hline No. & Question & Mean & S.D. & Rank & Level \\
\hline $\mathbf{1 1}$ & The company adopts applicable standards & 4.42 & .602 & $\mathbf{3}$ & High \\
\hline $\mathbf{1 2}$ & The company provides the required support to perform new operations & 4.41 & .602 & $\mathbf{4}$ & High \\
\hline $\mathbf{1 3}$ & The company trains employees on new operations that will be applied & 4.40 & .602 & $\mathbf{5}$ & High \\
\hline $\mathbf{1 4}$ & $\begin{array}{l}\text { The company provides employees with the needed tools to implement new } \\
\text { operations }\end{array}$ & 4.48 & .606 & $\mathbf{1}$ & High \\
\hline $\mathbf{1 5}$ & The company takes in consideration the feedback regarding new operations & 4.43 & .602 & $\mathbf{2}$ & High \\
\hline & The Grand mean & 4.44 & .596 & & High \\
\hline
\end{tabular}


Study sample attitudes regarding implementation of new operations were measured by (11-15) in table (6) .Statement means, ranged between (4.40 - 4.48). All of these means indicate positive attitudes .Table also indicates that paragraphs no.14 " The company provides employees with the needed tools to implement new operations.", ranked the first while paragraph no. 13 "The company trains employees on new operations that will be applied " ranked the last. Table indicates that the grand mean of all statements was (444), which corresponds to high level of respondent's agreement. The result indicates that customers prefere to have service of high quality, since high service quality will satisfy their need related to the service they received for the company

Table (7) Means and standard deviations of sample's responses regarding information technology

\begin{tabular}{|l|l|l|l|l|l|}
\hline No. & Question & Mean & S.D. & Rank & Level \\
\hline $\mathbf{1 6}$ & Reducing managerial and financial controls & 4.52 & .540 & $\mathbf{1}$ & High \\
\hline $\mathbf{1 7}$ & Provide the necessary information and data & 4.31 & .668 & $\mathbf{3}$ & High \\
\hline $\mathbf{1 8}$ & Redesign managerial Processes & 4.50 & .574 & $\mathbf{2}$ & High \\
\hline $\mathbf{1 9}$ & Coordinate managerial works between all managerial levels & 3.70 & 1.409 & $\mathbf{5}$ & High \\
\hline $\mathbf{2 0}$ & Complete all transactions quickly and accurately & 3.85 & 1.265 & $\mathbf{4}$ & High \\
\hline & The Grand mean & 4.18 & .671 & & High \\
\hline
\end{tabular}

Study sample attitudes regarding information technology were measured by (16-20) in table (7). Statement means, ranged between (3.85- 4.52). All of these mean indicate positive attitudes. Table also indicates that paragraph no. 16 "Reducing managerial and financial controls", ranked the first while paragraph no. 20 "Complete all transactions quickly and accurately "ranked the last. Table indicates that the grand mean of all statements was (4.18), which corresponds to high level of respondent's agreement. The result indicated that new operation related to electricity distribution is highly recommended by customers since it will improve the provided services.

Table (8) Means and standard deviations of sample's responses regarding employee's performance

\begin{tabular}{|l|l|l|l|l|l|}
\hline No. & Question & Mean & S.D. & Rank & Level \\
\hline $\mathbf{2 1}$ & Increase employees productivity & 4.00 & 1.213 & $\mathbf{4}$ & High \\
\hline $\mathbf{2 2}$ & Speed in providing service to subscribers & 3.56 & 1.621 & $\mathbf{7}$ & Medium \\
\hline $\mathbf{2 3}$ & Responding quickly to customer complaints & 4.17 & 1.209 & $\mathbf{1}$ & High \\
\hline $\mathbf{2 4}$ & Performing failures in the right time & 4.11 & 1.313 & $\mathbf{2}$ & High \\
\hline $\mathbf{2 5}$ & Developing company's employees performance & 3.74 & 1.519 & $\mathbf{6}$ & High \\
\hline $\mathbf{2 6}$ & Minimize routine daily work & 4.07 & 1.385 & $\mathbf{3}$ & High \\
\hline $\mathbf{2 7}$ & Save time spent on service delivery & 3.83 & 1.023 & $\mathbf{5}$ & High \\
\hline & The Grand mean & 3.93 & .962 & & High \\
\hline
\end{tabular}

Study sample attitudes regarding employees performance were measured by (21-27) in table (8). Statement means, ranged between (3.56- 4.17). All of these mean indicate positive attitudes. Table also indicates that paragraph no. 23 "Responding quickly to customer complaints." ranked the first while paragraph no. 22 "Speed in providing service to subscribers "ranked the last. Table indicates that the grand mean of all statements was (3.93), which corresponds to high level of respondent's agreement. The results indicate from the research sample perspective the impact of business process reengineering on the company's performance.

\section{Testing of Hypothesis}

The main hypothesis testing results

Ho: There is no statistically significant impact at $(\alpha \leq 0.05)$ level of business processes re-engineering application with its dimensions (procedures simplification, improving service quality, applying new processes and applying IT) on Jordan Electricity Distribution Company employee's performance to test this hypothesis multiple regression was used, the following table indicate the obtained results.

Table (9) Main Hypothesis Testing

\begin{tabular}{|c|c|c|c|c|c|c|c|}
\hline Re engineering & (R) & $\left(\mathrm{R}^{2}\right)$ & F-calculated & DF & Beta & $\mathbf{T}$ & Sig \\
\hline Procedures simplification & $879^{a}$ & 773 & \multirow{4}{*}{41.713} & 4 & -.350 & -.956 & .344 \\
\hline Improving service quality & & & & 49 & .372 & 2.086 & .042 \\
\hline Processes implementation & & & & 53 & -.263 & -.732 & .467 \\
\hline Information technology & & & & & .996 & 11.912 & .000 \\
\hline
\end{tabular}

Table (9) shows that the calculated F-value equals 41.713, which is more than the tabulated F-value (1.96); it also shows that the calculated significance value is $(0.000)$, which is less than $(\alpha \leq 0.05)$. 
Furthermore, the correlation coefficient $(\mathrm{R})$ value equals 0.771 and the coefficient of determination (R2) value equals 0.594 , which means that $59.4 \%$ of the variance in processes reengineering can be explained by the variance in employee's performance. The analysis results show that (improvement of service quality and information technology) dimensions influenced employee's performance while the rest did not affect, therefore null hypothesis is rejected and the alternative is accepted, this means that there is an impact of reengineering processes on Jordanian Electricity distribution employee performance.

\section{First sub hypothesis testing results}

Ho-1 There no statistically significant impact at $(\alpha \leq 0.05)$ level of procedures simplification on Jordanian Electricity Distribution Company employees performance

To test study sub hypotheses simple regression was used and the following tables indicate the obtained results.

Table (10) first sub hypothesis testing results

\begin{tabular}{|l|l|l|l|l|l|}
\hline Employees performance & $(\mathrm{R})$ & $\left(\mathrm{R}^{2}\right)$ & $($ Beta $)$ & $(\mathbf{T})$ & Sig \\
\hline Procedures simplifications & $302^{\mathrm{a}}$ & .091 & .302 & 2.287 & $0.026^{*}$ \\
\hline
\end{tabular}

Table (10) indicates that the correlation coefficient value is 0.302 and that the value of the coefficient of determination is 0.091 . This means that the variable procedures simplification accounts for $9.1 \%$ of the difference in employee's performance.

In addition, the value of the calculated value is (2.287) which are significant at the level of significance of 0.05 , and therefore the null hypothesis is rejected and accepts the alternative hypothesis, which states: "There is a significant statistical impact at the level of significance $(0.05 \alpha)$ of procedures simplification on Electricity Distribution Company employee's performance.

Ho-2 there no statistically significant impact at $\alpha \leq 0.05$ level of improving service quality on Jordanian Electricity Distribution Company employees performance

Table (11) Second sub hypothesis testing results

\begin{tabular}{|l|l|l|l|l|l|}
\hline Employees performance & $(\mathrm{R})$ & $\left(\mathrm{R}^{2}\right)$ & $\mathbf{( B e t a )}$ & $(\mathbf{T})$ & Sig \\
\hline Procedures simplifications & $304^{\mathrm{a}}$ & .093 & .304 & 2.304 & $0.025^{*}$ \\
\hline
\end{tabular}

Table (11) indicates that the correlation coefficient value is 0.304 and that the value of the coefficient of determination is 0.093 . This means that the variable improving service quality accounts for $9.3 \%$ of the difference in employee's performance. In addition, the value of the calculated value is (2.304) which are significant at the level of significance of 0.05 , and therefore the null hypothesis is rejected and accepts the alternative hypothesis, which states: "There is a significant statistical impact at the level of significance $(0.05 \alpha)$ of improving service quality on Electricity Distribution Company employee's performance.

Ho-3 There no statistically significant impact at $\alpha \leq 0.05$ level of applying new process on Jordanian Electricity Distribution Company employees performance

Table (12) third sub hypothesis testing results

\begin{tabular}{|l|l|l|l|l|l|}
\hline Employees performance & $(\mathrm{R})$ & $\left(\mathrm{R}^{2}\right)$ & $($ Beta $)$ & $(\mathbf{T})$ & Sig \\
\hline New Processes Implementation & .074 & .273 & .273 & 2.046 & $0.046^{*}$ \\
\hline
\end{tabular}

Table (12) indicates that the correlation coefficient value is 0.075 and that the value of the coefficient of determination is 0.273 . This means that the variable applying new processes accounts for $27.3 \%$ of the difference in employee's performance. In addition, the value of the calculated value is (2.046) which is significant at the level of significance of 0.05 , and therefore the null hypothesis is rejected and accept the alternative hypothesis, which states: "There is a significant statistical impact at the level of significance $(0.05 \alpha)$ of applying new processes on Electricity Distribution Company employees performance

Ho-4 there no statistically significant impact at $\alpha \leq 0.05$ level of applying information technology on Jordanian Electricity Distribution Company employees performance

Table (13) Fourth sub hypothesis testing results

\begin{tabular}{|l|l|l|l|l|l|}
\hline Employees performance & $(\mathrm{R})$ & $\left(\mathrm{R}^{2}\right)$ & $($ Beta) & $(\mathbf{T})$ & Sig \\
\hline Information Technology & $706^{\mathrm{a}}$ & .093 & .304 & 2.304 & $0.025^{*}$ \\
\hline
\end{tabular}


Table (13) indicates that the correlation coefficient value is 0.706 and that the value of the coefficient of determination is 0.840 . This means that the variable application of the new operations accounts for $84 \%$ of the difference in the performance of employees. In addition, the value of the calculated value is (4.073) which are significant at the level of significance of 0.05 , and therefore the null hypothesis is rejected and accepts the alternative hypothesis, which states: "There is a significant statistical impact at the level of significance $(0.05 \alpha)$ of information technology on Electricity Distribution Company employee's performance.

\section{Results}

Based on the analysis, the research revealed that there is a significant statistical impact of procedures simplification on Electricity Distribution Company employee's performance .The research also found there is a significant statistical impact of improving service quality on Electricity Distribution Company employee's performance. There is a significant statistical impact of applying new process In addition there is an ectricity Distribution Company employees performance There is a significant statistical impact of information technology on Electricity Distribution Company employees performance. The results can be attributed to the fact that reengineering process has an impact on all companies' activities, since it tackle the problem the company face and find a solution for such problem.

\section{Limitations of the Study}

The study findings were limited Jordanian Electricity distribution Company Therefore the research results cannot be generalized to cover all other services companies due to their different activates in addition the other limitation is the questionnaire distribution to the sample who are busy and have no time. The research subjects were not willing answer the questionnaire

\section{Implication}

Research findings provide several important managerial implications. First, company's managerial staff can exert their best efforts to improve distribution services through providing adequate training program their employees on an ongoing basis. Company's managerial staff should prepare a strategy that may enable employees to provide service with high quality.

\section{Areas for Further Research}

The research suggested future research regarding reengineering process on other fields either in industrial companies or other service sector.

\section{Conclusion}

The study concluded a number of results including that there is a significant statistical impact at of processes reengineering with its collective dimensions on Jordan Electricity Distribution Company employees performance. (Procedures simplification, improving service quality, implementation of new processes and implementation of Information technology) Jordanian Electricity Distribution Company employee's performance .1

\section{Recommendations}

The study recommended the need to processes re-engineering, taking into account departments that suffer from performance problems according to the rules of the re-engineering method in order to make fundamental changes that increase processes efficiency in order to improve the performance level and increase its effectiveness. There is a need to activate business process re-engineering on the rest of the units, in addition to make continues busies processes development in the company in order to increase or raise the performance of employees.

\section{References}

Ahmed Silo Abdul Hafiz, (2003) Engineering "How Re-Engineering is Applied, Dar Weal, Amman, Al-Kahlout, Ahmad Mahmoud Khalil (2017) The Relation of Process Re-Engineering with Competitive Advantage of Palestinian Universities in Gaza, Unpublished Master Thesis Al-Azhar University - Gaza

Al-Khudari, Dina and Al-Kasabah Muhammad Mufidi (2015) Impact of processes reengineering in Critical Performance Measures: A Comparative Study between Pharmaceutical and Chemical Companies in Jordan, Al-Quds Open University Journal for Research and Administrative and Economic Studies, Volume 1, Issue 1. 
Al-Kurdi, Ahmed (2010), Re-engineering of Administrative Works a Mean to Achieve Competitive for current organization. http://kenanaonline.com/users/ahmedkordy/topic

Al-Otaibi, Saad and Al-Hamal Rashed, (2004): Business processes re-engineering (reengineering in the public sector. Critical success factors), First National Conference on Quality, King Saud University, May 17-15.

Amer. S and Qebdeel Syed (2010) ,organizational Development, Dar El fker, Amman , Jordan

Amrita, M. A., A. and Sheriff, A. (2015) "Exploration of critical organizational climate factors impacting BPR implementation: A Survey of Indian companies", European journal of business and management, VOL 7 , Issue 10.

Dodkh, Mohamed Youssef (2017) The Effect of Business Process Reengineering in Improving the Efficiency of Electricity Distribution Company Public Shareholding in Jordan, Master Thesis Unpublished, Amman Arab University

HailekirosSibhato\&Ajit Pal Singh, (2012) Evaluation on BPR Implementation in 28. Ethiopian Higher Education Institutions. Global Journal of Management and Business Research,vol.12,pp.2

Hope N.Nzewi, 2Ugochukwu C.Nzewi, and Patrick Moneme,(2015) Business process reengineering and performance of courier service organizations in Anambrastate, Nigeria, American Journal of Social and Management Sciences, Vol 6, issue 24

Jad Al -Rab Syed (2009): Human Resource Management ,a strategic approach to organize competitive capabilities

Jalali, M., Maroofi, F., Navid, J. and Mohammady R., (2013) "Evaluation the relationship between ICT-adoption and business process reengineering in small and medium sized enterprises of Kermanshan province", International research journal of applied and basic sciences", VOL 4, Issue 3.

Qariuti, M. Kassem (2000): Organizational Behavior - Study of Individual and Collective Human Behavior in Different Organizations, Dar Al Shorouk for Publishing and Distribution, Amman

Sharma, R. and Kant, R. (2015) "HR issues and challenges in implementing business process reengineering in government organizations in India", European journal of business and management, VOL 7, Issue 19

Skarneh, Bilal Khalaf (2009): Contemporary Administrative Studies, Dar Al-Masirah for Publishing, Distribution and Printing, Jordan.

Sudhakar, G. (2010) The Role of IT in Business Process Reengineering Article, Economica, Vol 6, No 4 